\title{
A Discussion on the Characteristics of Tectonic Transformation and Its Mechanism of 2 nd Episode of Zhu-Qiong Movement in Zhu 1 Depression, South China
}

\author{
Yang Hu \\ Exploration and Development Research Institute, SINOPEC Shengli Oilfield Company, Dongying, China \\ Email: huyangsq052@163.com
}

How to cite this paper: Hu, Y. (2021). A Discussion on the Characteristics of Tectonic Transformation and Its Mechanism of 2nd Episode of Zhu-Qiong Movement in Zhu 1 Depression, South China. Journal of Geoscience and Environment Protection, 9, 1-12.

https://doi.org/10.4236/gep.2021.91001

Received: November 3, 2020

Accepted: December 31, 2020

Published: January 7, 2021

\begin{abstract}
Based on the detailed interpretation of high-accuracy 3D seismic data, the characteristics of regional unconformities, fracture systems, sedimentary filling and paleo-stress field in Zhu 1 depression were comprehensively analyzed. The results showed that 2nd episode of Zhu-Qiong movement was an important tectonic transformation that occurred during rifting, basin structure patterns above and below the regional angular unconformity caused by 2nd episode had distinct differences. The orientations of those basin-controlling faults changed from NE, NEE to EW, NWW, which indicated that the paleo-stress field veered from NNW extension clockwise to sub-NS extension and basin structures patterns transformed from NE, NEE strong rifting to sub-EW, NWW weak rifting. The depocenter showed seesaw-like migration from $S$ to $\mathrm{N}$. And the sedimentary systems transformed from semi-deep-deep lacustrine facies to braided river delta facies developed in shore-shallow lacustrine. Combined with its tectonic recombination of periphery plates that period, the mechanism of above tectonic transformation had direct correspondence to the readjustment of the Indian plate and the Pacific plate. The southward subduction of the proto-south China Sea is the direct cause of this tectonic transformation.
\end{abstract}

\section{Keywords}

Tectonic Transformation, Genetic Mechanism, 2nd Episode of Zhu-Qiong Movement, Zhu 1 Depression

\section{Introduction}

Pearl River Mouth Basin is located in the continental shelf to the slope of the 
northern South China Sea between the Taiwan and Hainan Island. It is a hydrocarbon basin which was formed on the Pre-Cenozoic fold basement. Pearl River Mouth Basin present in the structure of belting in north-south trend and block-faulting in east-west trend. From north to south, it includes 5 structural units: the north fault terrace zone, the north depression zone, the Central uplift belt, the south depression zone and the south uplift zone. This structural style was related to the north-east and the north-west direction distributed hidden faults (Cheng et al., 2003). Zhul depression is one of the secondary structural units in the north fault terrace, which was composed by 5 units, from east to west direction, they are the Enping sag, the Xijiang sag, the Huizhou sag, the Lufeng sag and the Hanjiang sag (Figure 1). Existing studies show that Zhu 1 depression had experienced the development stages of rift and depression during Paleogene, and now characterized with faulted in deep and depressed in shallow, and for marine sediment in the early stage and for continental sediment in the late (Li et al., 1998) (Lüdmann and Wong, 1999) (Morley, 2002) (Zhou et al., 2002) (Sun et al., 2006) (Zhang et al., 2007) (Shi et al., 2009) (Yu et al., 2009) (Cullen et al., 2010) (Wang et al., 2011) (Dai, 2013) (Xu et al., 2014). The stratum developed the early-Middle Eocene Wen-chang group which bounded by Tg in the bottom firstly, and followed by the Late Eocene to early Oligocene En-ping group which bounded by T80 in the bottom, and sediment at last with the Late Oligocene Zhuhai group which bounded by T70 in the bottom (Cui et al., 2009).

Numerous previous studies indicated that the rift stage of the Pearl River Mouth Basin had experienced two tectonic events (1st and 2nd episode of Zhu-Qiong movement) (Li, 1993). The 1st episode of Zhu-Qiong movement during the Early and Middle Eocene was the beginning of the rift stage, and the

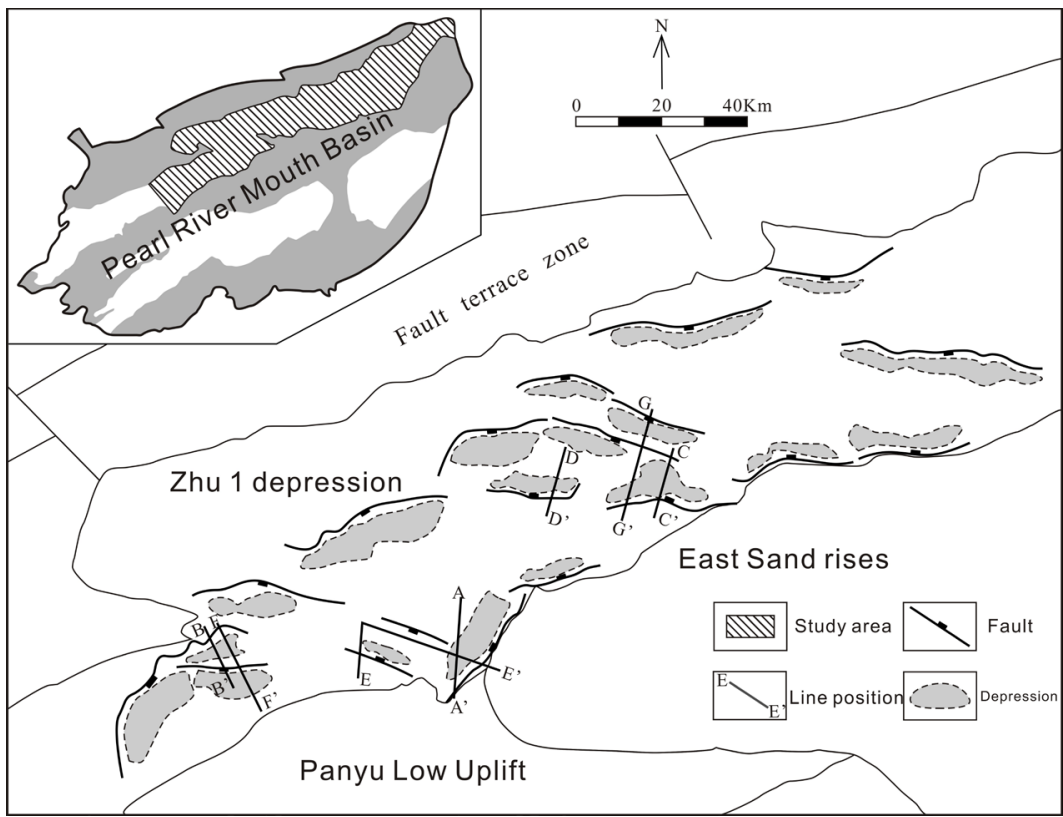

Figure 1. Regional location and structure of Zhu 1 depression. 
2nd episode of Zhu-Qiong movement during the Late Eocene-early Oligocene was the significant tectonic event. The differences of structural-sedimentary characteristics of the two tectonic events reflected the significant changes of the stress system and the tectonic framework during the history of basin development.

Based on the previous research results, this paper studied the unconformity surface, the fault system, the ancient stress field orientation and the sedimentary fill styles by using the high-precision 3D seismic data. Aiming at clarifying the evolution and the rules of the basin, we also investigated the relationship of time-space and discussed the mechanism of tectonic transitions.

\section{The Characteristics of the Unconformity Surfaces}

Unconformity surface in the sediment-layer is the direct recording of the tectonic movement, its formation often was related to the uplift of front curtain and the initial structural adjustment event of posterior curtain (Ren, 2004). The T80 is the regional angular unconformity surface formed during the structural transformation from 1st and 2nd episode of Zhu-Qiong movement (Wang et al., 2009). The structural styles mainly include truncation, folds and overlap in the profiling, but they have its own features in different sag.

The Xijiang sag mainly developed unconformity by folding. Large rollover anticline developed near to the main boundary fault, the strata close to boundary fault was thick and other side was thin, and reflected sedimentary features of rollover anticline and experienced strong extensional tectonic movements in the history. The top of anticline suffered significant truncation, and gentle Enping formation overlap above the anticline bounded by T80 in the bottom (Figure 2(a)).

The Enping sag mainly developed with truncation unconformity style. The layer of the Wenchang group had experienced strong block rotation movement.
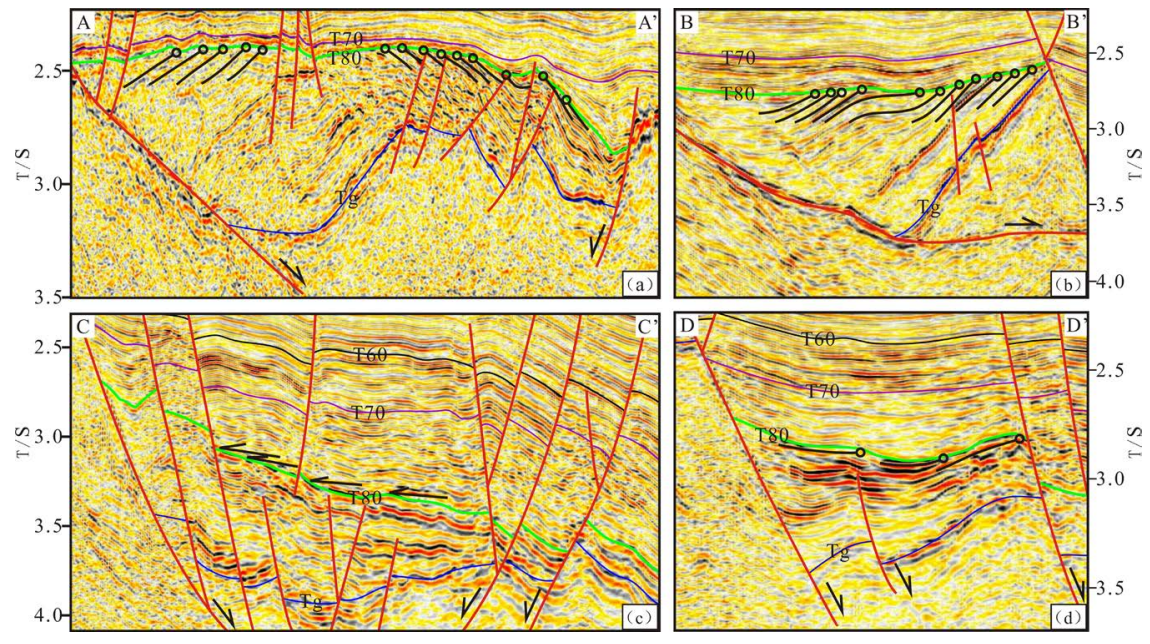

Figure 2. The seismic reflection characteristics of T80 Unconformity (location marked in Figure 1). 
They developed in the hanging wall of mainly basin controlled fault, and the high sites were truncated seriously. The En-ping group overlap above the truncated anticline bounded by T80 in the bottom (Figure 2(b)).

The Enping formation strata overlap above the Wenchang formation directly in Huizhou sag. It developed overlap unconformity style, we can see hardly the truncation in the profile (Figure $2(\mathrm{c})$ ). We also can find block rotation and truncation unconformity style in local place (Figure 2(d)), those features reflected the lifting of tectonic movement. Above all, we draw the conclusion that large angular unconformity style between upper and lower strata of interface T80 revealed the significant tectonic and sediment changes in the evolution of the basin.

\section{The Characteristics of Structural Movements}

The fault is the mainly developed style of structural movement in the Zhu 1 depression. The T80 formed after the Zhu-Qiong II movement, and it reflects the different faults system styles and the transformation of the basin, meanwhile, it revealed the change of the regional stress include the orientation and the strength in the Zhu 1 depression.

\subsection{The Change of the Faults System Characteristics}

Multiple directional fractures developed in the rifting stage of the Zhu 1 depression, there are mainly NE, NEE, NWW and EW-wards distributed. The NE and NEE-wards faults led the structural pattern of the basin to north-south zonation; The NE and NEE-wards faults sheared by the NWW-wards fractures into massive (chunk). The Basin present in the structure of banded in the north-south direction and the block patterns in the east-west direction (Zhong et al., 2014). The features of different layer near to the T80 have its own fracture style.

The sedimentary fractures mainly distributed in NE and NEE-wards in the Wenchang, meanwhile, a series of NWW and EW-wards distributed fractures developed (Figure 3(a)). The NE and NEE-wards faults have the most serious faulting strength, the EW-wards take the second place and the NWW-wards were the most slight (Figure 4).

The fractures in the Enping stage inherited the structural activities of Wenchang, besides, developed a series of EW-wards distributed faults as well. Sedimentary fractures mainly distributed in the EW and NWW-wards (Figure 3(b)). The strength of the inherit NE and NEE-wards fractures becoming slight or even haven't happened, the EW and NWW-wards fractures, strong strength, developed into basin controlled fracture (Figure 4).

Based on the above analysis, the developing features of the fracture system have changed sharply from the Wenchang group to the Enping group. Compared with the Wenchang group, the strength of the NE and NEE-wards fractures in the Enping group becoming slight or even have not happened, the nearly NE and NWW-wards fractures become strong, and developed a series of nearly EW-wards distributed faults, sedimentary fractures mainly distributed in 


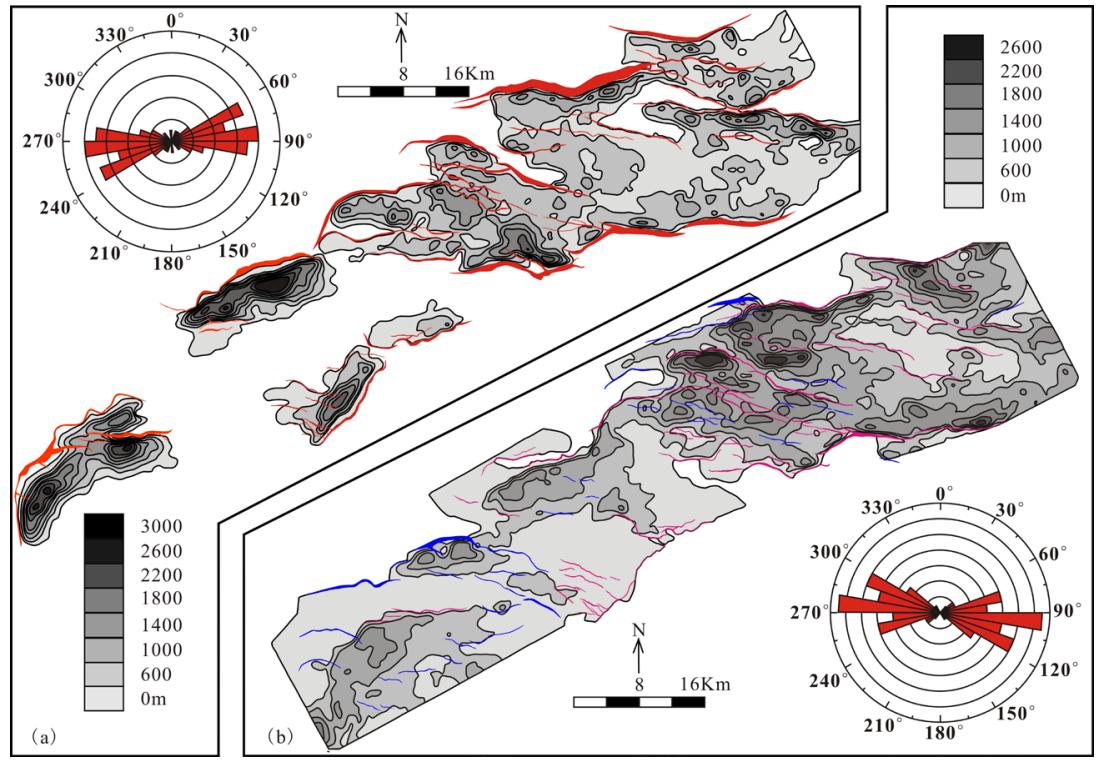

Figure 3. Major syndepositional faults and residual strata thickness during rifting in Zhu 1 depression.

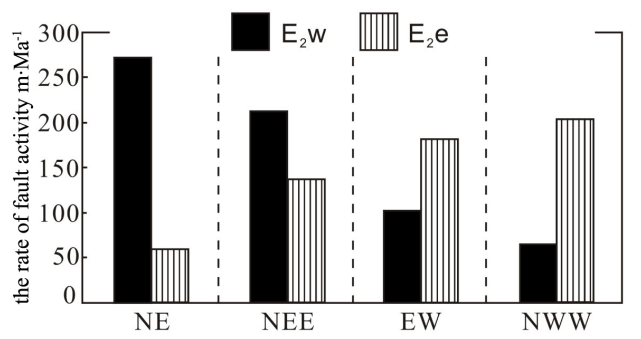

Figure 4. Activity rate of fault with various orientation during rifting in Zhu 1 depression.

the EW and NWW-wards. The obvious different distribute orientations and the active strength of two fracture systems reflected the different stress results.

\subsection{The Transform of the Ancient Stress Direction}

We can infer the direction of the ancient stress field based on the analysis of the mainly distributed orientation and the strength of the sedimentary fractures. The sedimentary fractures have the strongest strength and were distributed mainly in the EW and NWW-wards (Figure 3(a)) \& (Figure 4) in the Wenchang stage. These features reflect the NNW to SSE-wards extensional stress functioned on the basin. The mainly distributed direction of the sedimentary fractures changed into nearly EW and NWW-wards (Figure 3(a)), and become stronger. On the other side, the active strength of former fractures nearly distributed in the EW and NWW-wards declined seriously (Figure 4). These features revealed the change clockwise of the regional stress from NNW-SSE-wards to the N-Swards.

\subsection{The Transform of the Basin Structural Pattern}

The sag pattern, seriously affected by the basin controlled faults, mainly were 
half grabens or graben structure in the Wenchang group. The sags have small distribution area and isolated from each other in the large scales, as a result, the ancient geomorphological features presented as the many mountains and the lakes around each other (Figure 3(a)). The basin controlled faults in the Xijiang and Enping sag mainly distributed in the NE-NEE-wards, and manifested as the half graben structural and the strong chunk rotation movement with the features of low angle slope to flat or slab fractures (Figure 5(a) \& Figure 5(b)). On the other side, the basin controlled faults in the sag Huizhou mainly distributed in the NWW-wards, and the activities of the EW-wards distributed basin controlled fractures in the south stronger than the NWW-wards distributed in the north, and formed the asymmetric graben structure of faulted in the south part and overlapped in the north part (Figure 5(c)).

The transition process among different sags has its own style in the Enping stage. The direction of the basin controlled faults in the Xijiang and Enping sag, west of the basin, connected with each other tightly, turned from the NE and NEE-wards to the EW and NWW-wards. These faults mainly manifested as the half graben structural of the shovel-style fault controlled and the weaken chunk rotation movement with the features of high angle slope to flat or slab fractures in the profiling, and the isolated half-graben composed as a whole (Figure 5(a) \& Figure 5(b)). Besides, a series of nearly EW-wards distributed faults developed lately in the north uplift, meanwhile, the range of the basin expanded with the N-S-wards extension of the fault, as a result, the Panyu uplift in the south, relatively lower, receives deposits (Figure 5(a) \& Figure 5(b)). The distributed direction of the basin controlled faults of the Huizhou sag keep invariant, while the strength changed seriously. Compared with the Wenchang group, the strength of the NWW-wards fractures in the north was strong relatively and the nearly EW-wards fractures in the south were slight, and formed the asymmetric graben structure of faulted in the north part and overlapped in the south part. As a result, the uplift in the north sink under to the level and receiving deposit with the $\mathrm{N}$-wards expand of the basin range (Figure $5(\mathrm{c})$ ). The transform features of
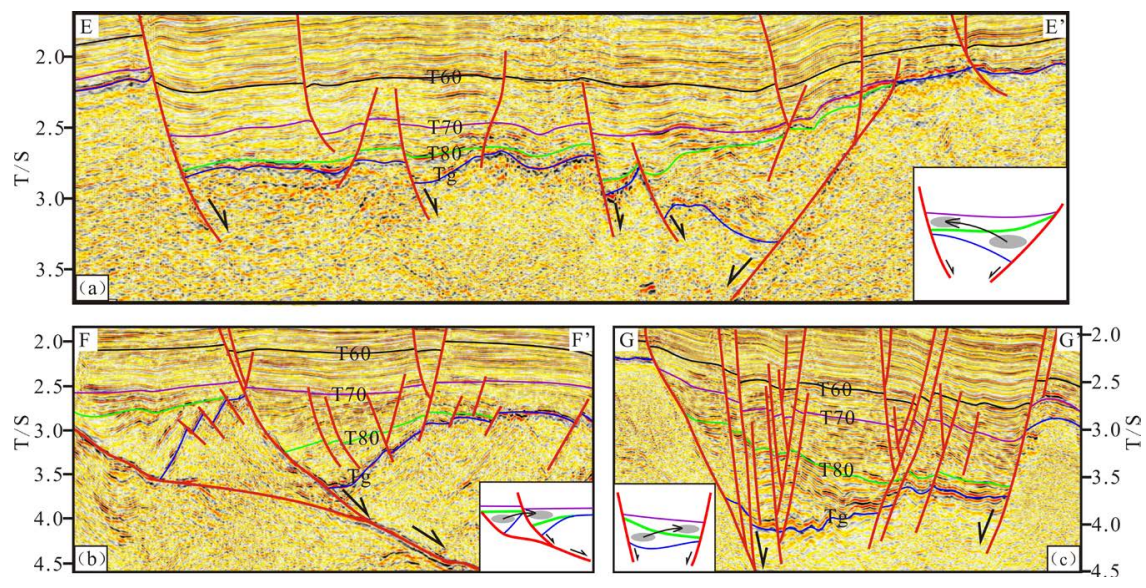

Figure 5. Typical seismic profiles in Zhu 1 depression (location marked in Figure 1). 
the basin were very obviously and the basin range have trend to expand sharply during the basin development through the Wenchang stage to the Enping stage.

\section{The Response of Sedimentary Characteristics}

For rift basins, the development of faults controlled the formation and evolution, and then determined the sedimentary framework. Therefore, the changes of fault systems' characteristics from the sedimentary stage of Wenchang formation to Enping formation resulted in the transition of basin pattern, besides, it determined the migration of sedimentary and the transition of sedimentary system.

\subsection{The Migration of Sedimentary Centre}

Based on the analysis of distributive maps of residual formation thickness in Wenchang and Enping stage, we found that in sedimentary stage of Wenchang formation, NE, NEE-trending basin-controlling faults of Enping and Xijiang sag in southwest had intense activity. NWW, EW-trending basin-controlling faults of Huizhou sag in northeast had weak activity (Figure 4), the sedimentary centre mainly located in southwest (Figure 3(a)); in sedimentary stage of Enping formation, NE, NEE-trending faults had graduate die out, the activity of pre-existent NWW, EW-trending faults enhanced significantly (Figure 4). From the sedimentary stage of Wenchang formation to Enping formation, activity of NE, NEE-trending and NWW, EW-trending faults varied alternatively, and it resulted in the sedimentary centre migrated from Enping and Xijiang sag to Huizhou sag (Figure 3(b)).

Concerned on individual sag, from the sedimentary stage of Wenchang to Enping formation, the controlling-basin faults of northwestern margin developed successively and its activity is intense. But the activity of controlling-basin faults of southeastern margin decreased or gradually die out, the sedimentary centre migrated from southeast to northwest (Figure 6).

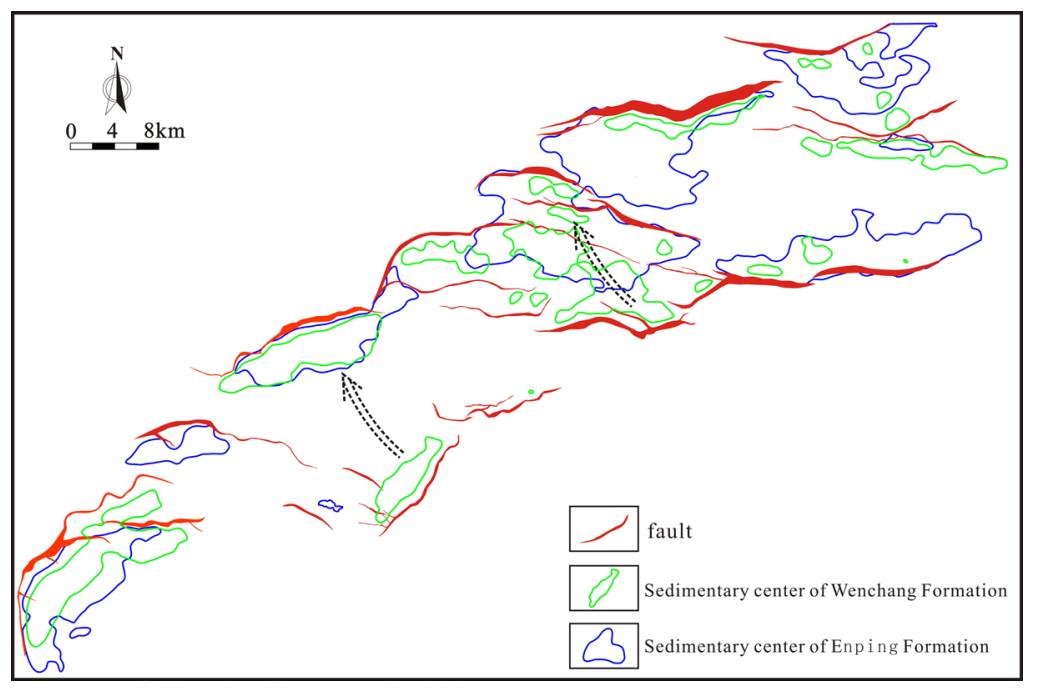

Figure 6. Migration of depocenter from Wenchang Formation to Enping Formation in Zhu 1 depression. 


\subsection{Changes of Sedimentary System}

In the sedimentary stage of Wenchang formation, the increasing rate of accommodation stage was fast, sedimentary source recharge was comparative limited., the sedimentary recharge was much less than the increase of accommodation stage. The centre of sub-sag was of fine sedimentary and it mainly developed semideep-deep lake subphase. In the sedimentary stage of Enping formation, the half-grabens which were isolated from each other linked together. The lake basin was wide and shallow, north-south trending sedimentary source recharge was sufficient. The deposition rate was greater than or equal to the increasing rate of accommodation stage. Particle size of sedimentary was comparative rough and it mainly developed braided river delta facies, costal shallow-lake facies and paludal facies (Zhong et al., 2014). The transition of sedimentary system brought up two different sets of hydrocarbon source rocks with different hydrocarbon generation capacity. For example, Wenchang formation mainly concluded fine sedimentary which was rich in aquatic algae, kerogen type of source rocks was good, the majorparent material was type-I and II 1 kerogen, and it mainly generated oil. It was the chief source rocks in this area. Enping formation was a set of coal-bearing strata source rock which was paludal phase. Organic matters mainly originated from higher plants. It had obvious continental characteristics and mainly included type-II 1 and III kerogen, the source rock is gas-prone. The transition of sedimentary system from Wenchang formation to Enping formation formed two sets of source rocks with different characteristics (Zhu et al., 2007) (Fu et al., 2007) (Li et al., 2009) (Li et al., 2013) (He et al., 2014). It had important significance on the oil and gas exploration of Zhu 1 depression.

\section{Discussion}

The tectonic evolution of Pearl River Mouth Basin was closely related to the interaction of Eurasian Plate, India Plate and Pacific Plate. The research above indicated that the second phase of Zhuqiong Motion was a significant tectonic change, the faults systems, stress regime, tectonic framework, and sedimentary system of the basin experienced significant changes, reflecting that two stages evolution of the basin were controlled by different regional dynamics condition (extensional regime of lithosphere).

In the sedimentary stage of Wenchang formation, the withdraw of NNWtrending subduction zone and the decrease of subduction velocity resulted that Pearl River Mouth Basin changed into extensional environment from compression environment (Figure 7(a)) under the background of soft collision between India Plate and Eurasian Plate, therefore, the basin entered into rifting stage. Before the rifting stage, Pearl River Mouth Basin was in Mesozoic active continental margin, volcanic-arc area with thickened crust and thinned mantle (South China and northern South China Sea), fore-arc area with normal crust and mantle (southern South China Sea) (Zhong et al., 2014), extension of lithosphere was shown as biaxial stretching wide rift extemnsion (Figure 7(a)). Under the 


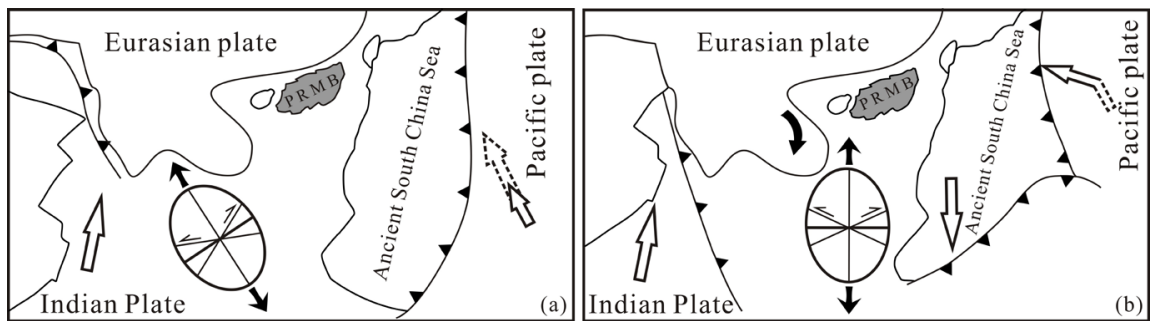

Figure 7. The regional background and lithosphere model of pearl river mouth basin during the period of rifting.

regional NNW-SSE trending extensional dynamic background, NE, NEE-trending faults of Zhu 1 depression were main-controlled faults, NWW and EW-trending faults belong to secondary regulating faults and its activity was relatively weak.

In the sedimentary stage of Enping formation, periphery India and Pacific Plate experienced evident tectonic recombination events. The direction of subduction of Pacific Plate changed into NWW trending from NNW trending and the subduction forward subducted beneath Eurasia continent with suddenly increased velocity (Engebretson et al., 1985) (Maruyama \& Send, 1986). Under the compressional settings of Pacific Plate accelerating subduction, in the west, the Continent-Continent hard collision between India Plate and Eurasian Plate resulted in the rotating extrusion of Indochina block, furthermore, it drove proto-South China sea subducted southward beneath Borneo massif. The drag force behind plates resulted in NS-trending extension of northern areas in South China sea including Pearl River Mouth basin (Hall, 2012) (Figure 7(b)).

Under the background of compression from both the east and the west sides and nearly NS-trending extension, Zhu 1 depression experienced evident tectonic transition, NNW-SSE trending was on longer the dominant extensional orientation, the pre-existing NE, NEE-trending controlling-sag faults of Enping and Xijiang sag actived weakly and gradually extinct. The activity intensity of pre-existing NWW, EW-trending faults in Huizhou sag matched with NS-trending extensional orientation. Its activities were significantly enhanced (Figure 4) and became main-controlled-fault, resulting in the migration of depocentres from Enping depression and Xijiang depression (southwest) to Huizhou depression (northeast).

Experienced adjustment of prophase taphrogeny, lithosphere structure of Pearl River Mouth basin was shown as normal features, it was of narrow rift extensional pattern and gradually thinned from land (north) to sea (south) (Figure 7(b)). The thinning lithosphere in south mainly developed pure shear extension, taphrogeny was centralized. The normal lithosphere structure in north mainly developed double-layer extension, including simple shear of upper crust and pure shear of lower crust. Zhu 1 depression was located in northern rift zone of Pearl River Mouth Basin. It was in normal continent lithosphere environment and mainly developed simple shear extension of one-way tension. As the north boundary of one-way tension, the pre-existing main-controlled faults in northwest margin of Zhu 1 depression was the main weak zone under the nearly 
NS-trending extension, and its stress was centralized, resulting in the main-controlled faults in northwest margin developed successively and actived intensely, and the activities of the basin controlling faults in southeast margin were significantly weakened or gradually extinct. Furthermore, it resulted in the migration of depcentres from southeast to northwest.

Thus it can been seen, 2nd episode of Zhu-Qiong movement tectonic transformation was related to adjusting events of periphery India and Pacific Plate, the southward subduction of proto-south China Sea was the direct cause of its formation. Combined with the researches of continental margin basin in the northern part of South China Sea, Southwest Taiwan basin, Southeast Hainan basin and Nansha block also exist similar tectonic events besides Pearl River Mouth basin. A serious of tectonic events coupled existed (Lei et al., 2011) (Zhang, 2012), reflected that the influence scope of periphery plates' recombination events was regional, it might provide beneficial clues for the formation and evolution of South China Sea.

\section{Conclusion}

1) The 2nd episode of Zhu-Qiong movement is one of the significant tectonic change events during the rift depression, and formed the T80 regional angular unconformity surface. The unconformity style mainly includes truncation, folds and overlap. The features of upper and lower sediment layer of interface T80 changed sharply.

2) Characteristics of the 2nd episode of Zhu-Qiong movements are: advantage distributed direction of the sedimentary faults turned from NEE and NE to NNW and NWW, and developed a series of EW distributed faults. The regional extension orientation clockwise changed from NWW to NS; the basin pattern transformed from NE and NEE distributed strong rifts to EW and NWW distributed weak rifts.

3) The sedimentary response characteristics of the 2nd episode of Zhu-Qiong movement are: the depocenter showed seesaw-like migration from $\mathrm{S}$ to $\mathrm{N}$; the sedimentary systems transformed from semi-deep-deep lacustrine facies to braided river delta facies developed in shore-shallow lacustrine.

4) The mechanism of above tectonics transformation had direct correspondence to the readjustment of the Indian plate and the Pacific plate. The southward subduction of the proto-south China Sea is the direct cause of this tectonic transformation.

\section{Conflicts of Interest}

The author declares no conflicts of interest regarding the publication of this paper.

\section{References}

Cheng, C., Shi, H. S., Xu, S. C. et al. (2003). Oil and Gas Reservoir Formation Condition in the Tertiary System of Pearl River Mouth Basin (Eastern) (pp. 31-50). Beijing: 
Science Press.

Cui, S. S., He, J. X., Chen, S. H. et al. (2009). Development Characteristics of Pearl River Mouth Basin and Its Geological Conditions for Oil and Gas Accumulation. Natural Gas Geoscience, 20, 385-389.

Cullen, A., Reemst, P., Henstra, G., Gozzard, S., \& Ray, A. (2010). Rifting of the South China Sea: New Perspectives. Petroleum Geoscience, 16, 273-282. https://doi.org/10.1144/1354-079309-908

Dai, Y. D. (2013). Paleogene Tectonic Evolution and Sedimentation in South Xijiang Sag, Pearl River Mouth Basin. China Offshore Oil and Gas, 25, 1-3.

Engebretson, D. C., Cox, A., \& Gordon, R. G. (1985). Relative Motions between Oceanic and Continental Plates in the Pacific Basin. Geological Society of America Special Papers, 206, 1-60. https://doi.org/10.1130/SPE206-p1

Fu, N., Ding, F., He, S. B. et al. (2007). Source Rocks Evaluation and Reservoir Characteristics Analysis in Enping Sag, Pearl River Mouth Basin. China Offshore Oil and Gas, 19, 295-298.

Hall, R. (2012). Late Jurassic-Cenozoic Reconstructions of the Indonesian Region and the Indian Ocean. Tectonophysics, 570, 27-30. https://doi.org/10.1016/j.tecto.2012.04.021

He, J. X., Zhang, W., Yan, W. et al. (2014). Episodic Tectonic Evolution, Basin Types and Hydrocarbon Accumulation in Chinese Marginal Basins. Marine Geology \& Quaternary Geology, 34, 121-130. https://doi.org/10.3724/SP.J.1140.2013.02121

Lei, C., Ren, J. Y., Li, X. S. et al. (2011). Structural Characteristics and Petroleum Exploration Potential in the Deep-Water Area of the Qiongdongnan Basin, South China Sea. Petroleum Exploration and Development, 38, 560-564.

Li, P. L. (1993). Cenozoic Tectonic Movement in the Pearl River Mouth Basin. China Offshore Oil and Gas (GEOLOGY), 7, 13-17.

Li, S. F., Xu, S. H., Shi, H. S. et al. (2013). Characteristics of Paleogene Source Rocks and Prediction of Petroleum Resources in Huizhou Depression, Pearl River Mouth Basin. Earth Science-Journal of China University of Geoscience, 38, 115-120.

Li, S. T., Lin, C. S. et al. (1998). Episodic Rifting and Its Dynamical Process in North Continental Margin of South China Sea, and the Tectonic Event from 10 Ma. Chinese Science Bulletin (in Chinese), 43, 797-810.

Li, Y. C., Tao, W. X., Sun, Y. M. et al. (2009). Classification and Distribution of Oil in Huizhou Depression of Pearl River Mouth Basin. Acta Petrolei Sinica, 30, 831-834.

Lüdmann, T., \& Wong, H. K. (1999). Neotectonic Regime on the Passive Continental Margin of the Northern South China Sea. Tectonophysics, 311, 120-130. https://doi.org/10.1016/S0040-1951(99)00155-9

Maruyama, S., \& Send, T. (1986). Orogeny and Relative Plate Motions: Example of the Japanese Islands. Tectonophysics, 127, 305-329. https://doi.org/10.1016/0040-1951(86)90067-3

Morley, C. K. (2002). A Tectonic Model for the Tertiary Evolution of Strike-Slip Faults and Rift Basins in SE Asia. Tectonophysics, 347, 195-210. https://doi.org/10.1016/S0040-1951(02)00061-6

Ren, J. Y. (2004). Tectonic Significance of S6' Boundary in Dongying Depression, Bohai Gulf Basin. Earth-Science Journal of China University of Geosciences, 29, 72-76.

Shi, H. S., Yu, S. M., Mei, L. F. et al. (2009). Features of Paleogene Episodic Rifting in Huizhou Fault Depression in the Pearl River Mouth Basin. Natural Gas Industry, 29, 35-37.

Sun, Z., Zhong, Z. H., Zhou, D. et al. (2006). Research on the Dynamics of the South 
China Sea Opening: Evidence from Analogue Modeling. Science in China (Series D): Earth Sciences, 36, 797-810. https://doi.org/10.1007/s11430-006-1053-6

Wang, J. H., Liu, L. H., Chen, S. H. et al. (2011). Tectonic-Sedimentary Responses to the Second Episode of the Zhu-Qiong Movement in the Enping Depression, Pearl River Mouth Basin and Its Regional Tectonic Significance. Acta Petrolei Sinica, 32, 590-595.

Wang, J. H., Wang, H., Xiao, D. Q. et al. (2009). Determination of Second-Order Stratigraphic Sequences in Continental Extensional Basins. Acta Petrolei Sinica, 30, 869-875.

Xu, J., Ben-Avraham, Z., Kelty, T., \& Yu, H. S. (2014). Origin of Marginal Basins of the NW Pacific and Their Plate Tectonic Reconstructions. Earth-Science Reviews, 130, 154-196. https://doi.org/10.1016/j.earscirev.2013.10.002

Yu, S. M., Shi, H. S., Mei, L. F. et al. (2009). Analysis of Tense-Shearing Characteristics of Huizhou Paleogene Fault Depression in Pearl River Mouth Basin. Petroleum Geology \& Experiment, 31, 485-489.

Zhang, G. C., Mi, L. J., Wu, S. G. et al. (2007). Deepwater Area-The New Prospecting Targets of Northern Continental Margin of South China Sea. Acta Petrolei Sinica, 28, $18-21$.

Zhang, L. (2012). Tectonic Evolution of the South China Sea and a Numerical Modeling (pp. 110-111). Qingdao: The University of Chinese Academy of Sciences (Institute of Oceanology).

Zhong, Z. H., Shi, H. S., Zhu, M. et al. (2014). A Discussion on the Tectonic-Stratigraphic Framework and Its Origin Mechanism in Pearl River Mouth Basin. China Offshore Oil and Gas, 26, 21-24.

Zhou, D., Chen, H. Z., Wu, S. M. et al. (2002). Opening of the South China Sea by Dextral Splitting of the East Asian Continental Margin. Acta Geologica Sinica, 76, 180-190.

Zhu, J. Z., Shi, H. S., \& Deng, H. W. (2007). Geochemistry of Source Rocks in Paleogene Sequence of Huizhou Depression Pearl River Mouth Basin. Natural Gas Geoscience, 18, 710-714. 